\title{
Prognostic value of Amino Terminal Pro B-type Natriuretic Peptide (NT-proBNP) in patient with severe sepsis and septic shock in an ICU of tertiary care hospital of Bangladesh.
}

*Tarikul Hamid ${ }^{1}$ * Rozina Sultana ${ }^{2}$, A.S.M. Areef Ahsan ${ }^{3}$, Kaniz Fatema ${ }^{4}$, Fatema Ahmed ${ }^{5}$, Debasish Kumar Saha $^{6}$, Madhurima Saha ${ }^{7}$, Suraiya Nazneen ${ }^{8}$.

\begin{abstract}
Background: Severe sepsis and septic shock are the leading cause of ICU admission. Despite the adequate resuscitation, septic shock is frequently associated with multiple system organ failure (MSOF) and death. This study examined the clinical utility of the level of NT-proBNP as an indicator of outcome in severe sepsis and septic shock.

Objectives: to find relationship between level of NT-Pro-BNP and the outcome of the patients of severe sepsis and septic shock.

Design: This Prospective observational study done in ICU of BIRDEM General Hospital.

Method: All consecutive patients who were diagnosed as severe sepsis and septic shock according to SSC (Surviving Sepsis Campaign) guidelines fulfilling the selection criteria were included in the study. Informed written consent was taken from patient's first degree relatives. Just after admission of severe sepsis and septic shock patients into ICU and development of severe sepsis or septic shock of previously admitted ICU patients, blood sample for serum NT-proBNP level was sent to hospital laboratory. 28 days were taken as follow up period for all patients in this study. Outcome was measured by mortality. Those who were discharged or transferred were classified as survivors and those who were died, categorized as non survivors. Those who were neither discharged nor dead during the study period were classified as survivors. Patient's resusci-tation and management were done according to the standard ICU protocol of BIRDEM General Hospital.

Result: A total 127 of patients fulfilled the criteria of sepsis and septic shock and study inclusion criteria during the study period. The mean \& SD of age in this study was $63.69 \pm 17.79$ years. $52 \%(n=66)$ were male \& $48 \%(n=61)$ were female. Here DM was the most common (83.5\%) comorbidity and predominant diagnoses were Pneumonia $(58.3 \%)$ \& UTI (30.7\%). Among 127 patients, 24.4\% $(n=31)$ were in septic shock and $75.6 \%(n=96)$ patients present with severe sepsis. Level of NT-proBNP of severe sepsis patients were $4608.64 \pm 7712.12 \&$ Level of NT-proBNP of septic shock patients were $19239.06 \pm 13058.05(P<0.0001)$. Among $31(24.4 \%)$ septic shock patients, 32.2\% $(n=10)$ patients were survivor and NT-proBNP level was $7333.50 \pm 10624 \mathrm{pg} / \mathrm{ml} ; 67.8 \%(n=21)$ patients were non survivor and NT-proBNP level was $24908.38 \pm 10017.87 \mathrm{pg} / \mathrm{ml}(P<0.001)$. In this study among $96(75.6 \%)$ patients with severe sepsis, $88.7 \%(n=86)$ were survivor and NT-proBNP level was $2436.41 \pm 3755.03 \mathrm{pg} / \mathrm{ml} ; 11.3 \%(\mathrm{n}=11)$ patients were non-survivors and NT-proBNP level was $21238.36 \pm 10095.34 \mathrm{pg} / \mathrm{ml}(P<0.0001)$.

Conclusion: Severe sepsis and septic shock are the leading cause of ICU admission and also leading cause of death. Our study showed that, elderly with diabetes mellitus had developed more sepsis. Pneumonia and UTI are commonest cause of sepsis. Sepsis causes extreme inflammatory reactions involving all organs of whole body including heart, causing release of NT-proBNP. Raised level of this biomarker associated with increased rate of mortality.
\end{abstract}

Key words: Amino Terminal Pro B-type Natriuretic Peptide (NT-proBNP), sepsis.

\section{Introduction:}

Severe sepsis and septic shock are common and deadly disease with major public health implication. Sepsis is now the $10^{\text {th }}$ most common cause of death in United Sates ${ }^{1}$. Approximately 7,50,000 patients develop sepsis each year, among which 2,25,000 $\mathrm{die}^{2}$. Though the term 'Sepsis' persisted for more than 2700 years with essentially unchanged meaning; worldwide accepted definitions of severe sepsis and septic shock have been formulated since early $1990 \mathrm{~s}^{3}$. So, when sepsis is associated with hypoperfusion or single organ dysfunction, become severe sepsis. When hypoperfusion in severe sepsis persist in spite of adequate fluid resuscitation and requiring vasopressors, it is called septic shock ${ }^{4}$. Massive resources have been invested in developing and evaluating potential therapies and considerable effort has been undertaken to understand the systemic inflammation and multiple-system organ failure characteristics of severe sepsis $^{5,6}$. The septic response involves an extremely complex chain of events involving inflammatory process, hormonal \& cellular reactions and circulatory derangements ${ }^{7,8}$. Sepsis develops rapidly and leads to high mortality rate and also high treatment costs ${ }^{9}$. Estimation of prognosis in the ICU may be challenging and in a patient population with sepsis and septic shock in ICU - although high mortality rates are expected - a simple, reproducible and reliable method for stratifying risk of death is highly desirable ${ }^{10}$. It is crucial to evaluate the severity of sepsis and provide early interventions to prevent or to reduce sepsis induced mortality. There have been many studies involving the indicators by which the severity and prognosis of sepsis can be evaluated. Procalcitonin, 
C-reactive protein, and protein $\mathrm{C}$ have been widely identified as predictors of sepsis. Newer understanding of pathophysiology of sepsis and sepsis induced multi-organ failure- now focus on biomarkers of cardiac dysfunction, like natriuretic peptides- ANP, BNP, NT-proBNP. Those natriuretic peptides were mainly used as predictors of cardiac dysfunctions- myocardial infarction, congestive cardiac failure $^{11}$. Myocardial depression is observed in $24 \%$ to $44 \%$ of septic patients ${ }^{12}$. Cardiac dysfunction in sepsis manifest as an acute increase in ventricular volume and deterioration of left ventricular ejection fraction associated with cardiac myocyte mechanical failure ${ }^{11}$. Early identification of sepsis and aggressive interventions for sepsis can have impact on outcome. It is also important that, early identification of patient at high risk of mortality after ICU admission may have therapeutic interventions such as changes in therapeutic protocols or further diagnostic procedures to prevent shock and multi organ failure and could have impact on ultimate patients' outcome. APACHE II, Sepsis Organ Failure Assessment (SOFA), Simplified Acute Physiology Score (SAPS) scores can predict mortality in septic patients quite well ${ }^{13,14}$. But complexity of those scores cause less user friendly in day to day use, and lack of novel blood markers for the diagnosis and specific monitoring of patients with sepsis. So, a fast, simple and cost effective method to enhance risk stratification in septic patient is needed.

Studies showed that BNP and NT-proBNP may serve as useful markers of myocardial dysfunction and may help differentiate between survivors and non survivors of severe sepsis and septic shock ${ }^{11,15}$.

This study will determine the clinical utility of the level of NT-proBNP as an indicator of outcome in severe sepsis and septic shock.
1. * Dr. Tarikul Hamid, Medical Officer.
2. * Dr. Rozina Sultana, Medical Officer.
3. Prof. A.S.M. Areef Ahsan, Head of the Department.
4. Dr. KanizFatema, Associate Professor.
5. Dr. Fatema Ahmed, Associate Professor.
6. Dr. Debasish Kumar Saha, Registrar.
7. Dr. Madhurima Saha, Registrar.
8. Dr. Suraiya Nazneen, Registrar.

Dept. of Critical Care Medicine, BIRDEM General Hospital, Shahbag, Dhaka 1000

\section{Corresponding Author:}

Dr. Tarikul Hamid

MD (Critical Care Medicine)

Medical Officer

Dept. of Critical Care Medicine

BIRDEM General Hospital

Cell : +88 01911099390

Email: tarikcox@gmail.com

*First Two Authors Should be considered as primary author for their equal contribution

\section{Method:}

This prospective observational study was carried out in the Department of Critical Care Medicine (ICU) of BIRDEM General Hospital, Dhaka from $1^{\text {st }}$ February 2016 to $31^{\text {st }}$ January 2017. All adult patients admitted in Department of Critical Care Medicine with the features of severe sepsis and septic shock who were initially entitled for the study purpose. Patient with myocardial infarction, acute left ventricular failure, decompensated heart failure \& pregnant woman were excluded. All consecutive patients who were diagnosed as severe sepsis and septic shock according to SSC (surviving sepsis campaign) guidelines and fulfilling the study selection criteria were included in the study. Informed written consent was taken from patient's first-degree relatives.

Just after admission of severe sepsis and septic shock patients into ICU and development of severe sepsis or septic shock of previously admitted ICU patients, blood sample for serum NT-proBNP level was sent to hospital laboratory. Here NT-proBNP level was measured at biochemistry laboratory by analyzer named Elecsys NT-proBNP; Roche diagnostics, USA, where measuring range is $5-35,000 \mathrm{pg} / \mathrm{ml}$ and normal value is less than $125 \mathrm{pg} / \mathrm{ml}$.

28 days was taken as follow up period for all patients in this study. Outcome were measured by mortality. Those who were discharged or transferred to ward/cabin were classified as survivors and those who were died, categorized as non survivors.

Those who were neither discharged nor died during the study period were classified as survivors.

Patient's resuscitation and management were done according to the standard ICU protocol of BIRDEM General Hospital.

Study patients would bear the cost of the relevant investigations as tests were routinely done in the departments as part of management. Data was recorded in pre-tested structured data sheet and analyzed by using Statistical Package for Social Sciences (SPSS) software (version 17).

For the purpose of this study, level of NT-proBNP, biomarkers and organ dysfunction scores were analyzed in all patients enrolled in the study. Descriptive statistics were used to summarize patient characteristics. Here categorical data were presented as frequency and percentage; numerical data were presented as Mean and Standard Deviation. The standard Chi square test was used for qualitative variables and two sample t-test for quantitative variables. P-value less than 0.05 was considered statistically significant. Ethical approval was taken from the Institutional Review Board (IRB), BIRDEM General Hospital prior to the commencement of the study.

\section{Results:}

During the study period among 1231 patients a total 127 patients have fulfilled the criteria of sepsis and septic shock. Therapy was initiated in the intensive care unit, including central venous and arterial catheterization, antibiotics, fluid resuscitation, mechanical ventilation, vasopressors and inotropes when appropriate. Results of level of NT-proBNP 
Bangladesh Crit Care J September 2018; 6 (2): 65-70

measured and recorded. The findings of the study obtained from data analysis are presented below.

Table 1 : Distribution of patients by their age

\begin{tabular}{lcc}
\hline Age (years) & Frequency (n) & Percentage (\%) \\
\hline$\leq 40$ & 6 & 4.7 \\
$41-50$ & 15 & 11.8 \\
$51-60$ & 32 & 25.2 \\
$61-70$ & 43 & 33.8 \\
$71-80$ & 16 & 12.6 \\
$\geq 81$ & 15 & 11.8 \\
Total & $\mathbf{1 2 7}$ & $\mathbf{1 0 0 . 0 0}$ \\
\hline
\end{tabular}

Mean $\pm \mathrm{SD}=63.69 \pm 17.79$; range $=20$ - 96 years

\section{Gender distribution:}

Figure 1 Shows pie chart of gender distribution of the patients

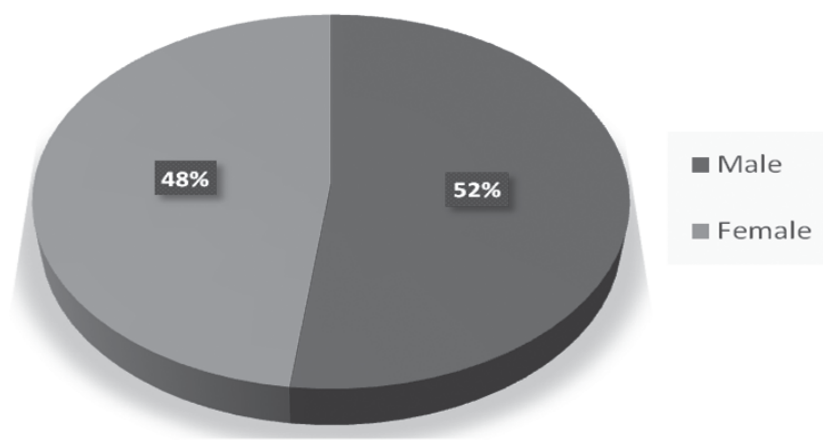

Fig 1

Table 2: Baseline characteristics of the patient with Severe sepsis group

\begin{tabular}{lcc}
\hline Variables & Mean \pm SD & Range (Min-max) \\
\hline Systolic BP (mmHg) & $115 \pm 23$ & $70-170$ \\
Diastolic BP (mmHg) & $69 \pm 14$ & $30-100$ \\
MAP & $84.8 \pm 14.6$ & $43-117$ \\
Hb\% (gm/dl) & $10.5 \pm 1.9$ & $6.4-15.2$ \\
TC & $16881 \pm 8197$ & $1000-58300$ \\
Platelet & $244437 \pm 1$ & $6000-680000$ \\
S. Creatinine (mg/dl) & $2.37 \pm 2.37$ & $0.6-12.2$ \\
NT-proBNP (pg/ml) & $4608.64 \pm 7712.12$ & $60-35000$ \\
$\begin{array}{l}\text { Use of mechanical } \\
\text { ventilation n (\%) }\end{array}$ & $28(29.2)$ & \\
$\begin{array}{l}\text { Duration of ICU } \\
\text { stay (days) }\end{array}$ & $7.4 \pm 5.0$ & $1-21$ \\
\end{tabular}

Table 3: Baseline characteristics of the patient with septic shock group

\begin{tabular}{lcc}
\hline Variables & Mean \pm SD & Range (Min-max) \\
\hline Systolic BP (mmHg) & $102 \pm 23.8$ & $70-160$ \\
Diastolic BP (mmHg) & $58.7 \pm 16.3$ & $30-80$ \\
MAP & $72.96 \pm 18.2$ & $43-107$ \\
Hb\% (gm/dl) & $9.6 \pm 2.15$ & $5.9-15.7$ \\
TC & $20774.5 \pm 8781.9$ & $15000-38400$ \\
Platelet & $158337.4 \pm 1.2$ & $25400-612000$ \\
S. Creatinine (mg/dl) & $2.49 \pm 1.86$ & $0.9-7.9$ \\
NT-proBNP (pg/ml) $19239.06 \pm 13058.05$ & $724-35000$ \\
Use of mechanical & & \\
ventilation n (\%) & $24(77.4)$ & $1-15$ \\
$\begin{array}{l}\text { Duration of ICU } \\
\text { stay day }\end{array}$ & $5.6 \pm 3.7$ & \\
\hline
\end{tabular}

Fig 2 \& 3 shows different types of comorbidities and diagnoses of study population

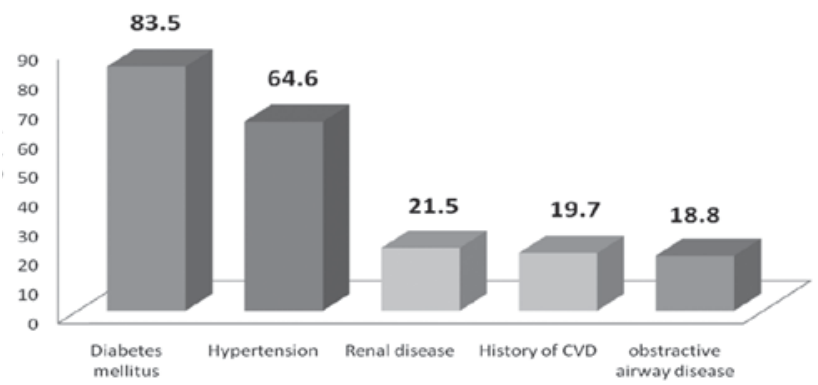

Figure 2: Bar chart of Associated co-morbidities of the patients

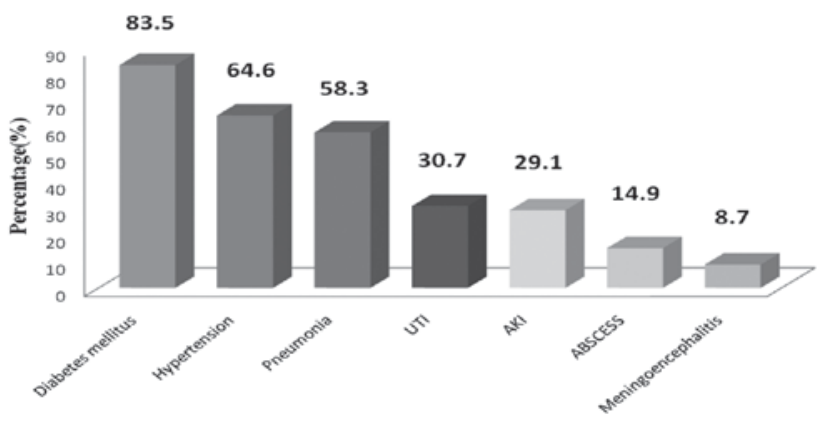

Figure 3: Bar chart of diagnoses of the patients 
Table 4: Proportion of survivor and non-survivor in severe sepsis and septic shock

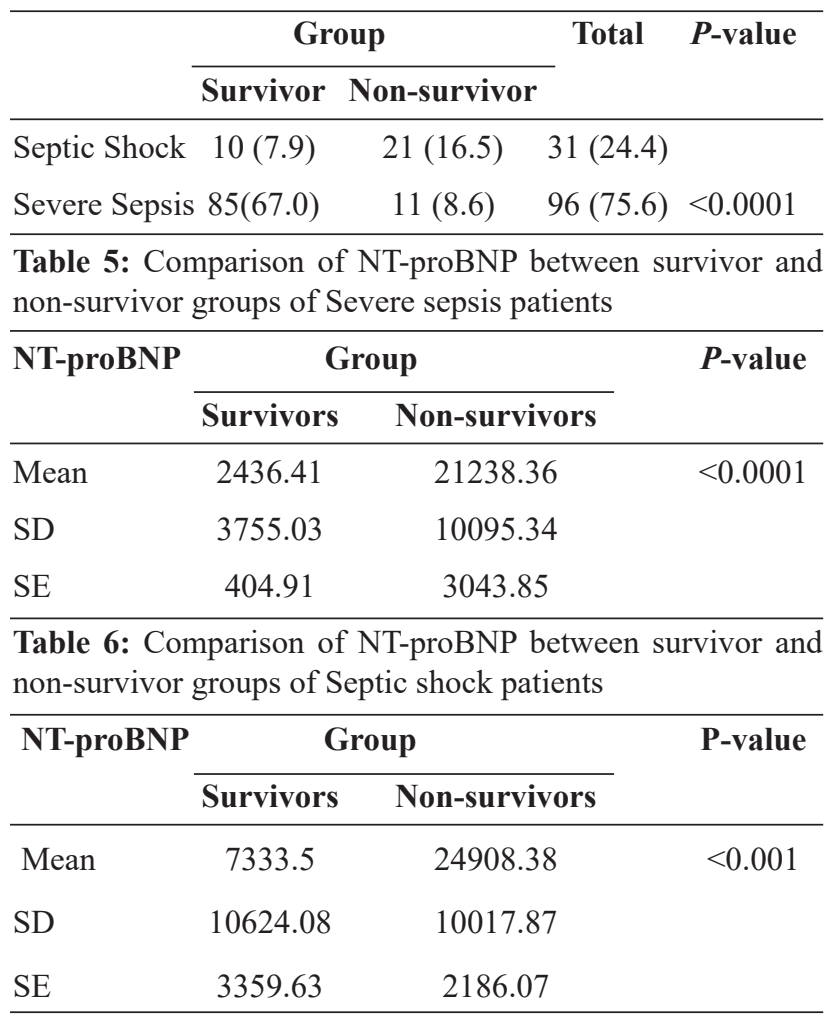

Table 7: Comparison of NT-proBNP between severe sepsis and Septic shock patients

\begin{tabular}{lccc}
\hline NT-proBNP & Severe sepsis & Septic shock & P-value \\
\hline Mean & 4608.64 & 19239.06 & $<0.0001$ \\
SD & 7712.12 & 13058 & \\
SE & 787.11 & 1345.29 &
\end{tabular}

\section{Discussion:}

Severe sepsis and septic shock are very common in ICU. In this study a total 127 of patients fulfilled the criteria of sepsis and septic shock and study inclusion criteria during the study period. The mean \& SD of age in this study were $63.69 \pm$ 17.79 years. Commonest age range was 51-70 (59.0\%) indicating elderly are more prone to develope severe sepsis and septic shock.

Angus et $\mathrm{al}^{9}$. epidemiologic studies found that, severe sepsis are difficult to compare, not only because their results are influenced by their date of implementation and the type of ICU analyzed, but also because severe sepsis is a highly heterogeneous condition.

Guidetet $\mathrm{al}^{16}$. compared non-severe sepsis patients with severe sepsis patients and found that severe sepsis patients were significantly older and had male predominance. In our study $52 \%(n=66)$ were male \& $48 \%(n=61)$ were female.

Angus et $\mathrm{al}^{9}$. describe the epidemiology of severe sepsis in the United States: analysis of incidence, outcome, and associated

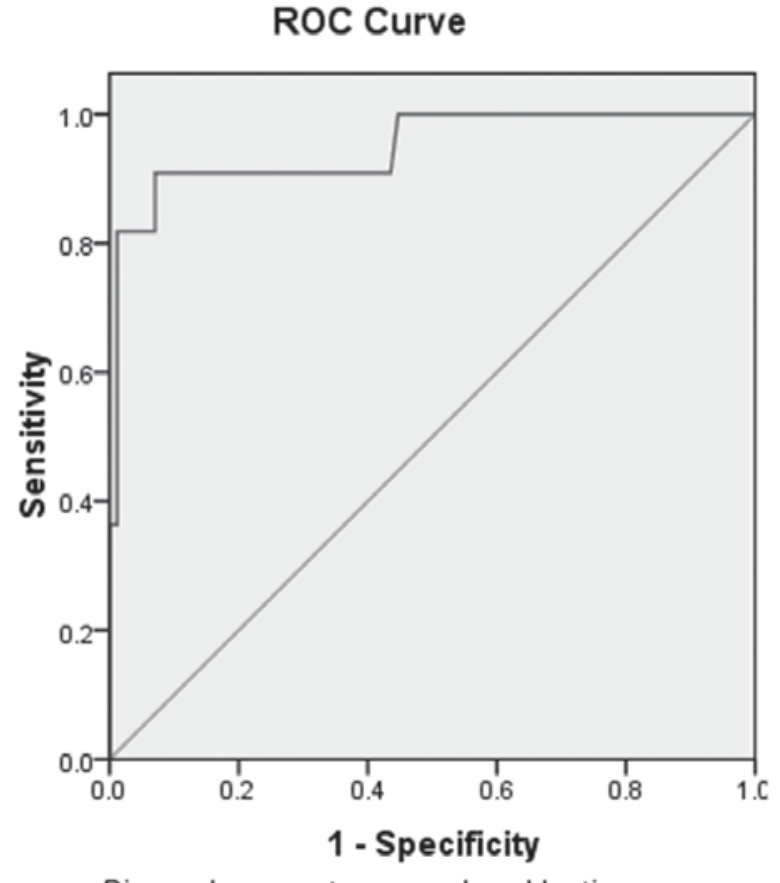

Diagonal segments are produced by ties.

Figure 4: ROC curve of NT-proBNP in prediction of outcome (severe sepsis group)

[AUC $=0.948]$, cut-off value $9291.5 \mathrm{pg} / \mathrm{ml}$ with sensitivity $=$ $90.9 \%$, specificity $=92.9 \%$.

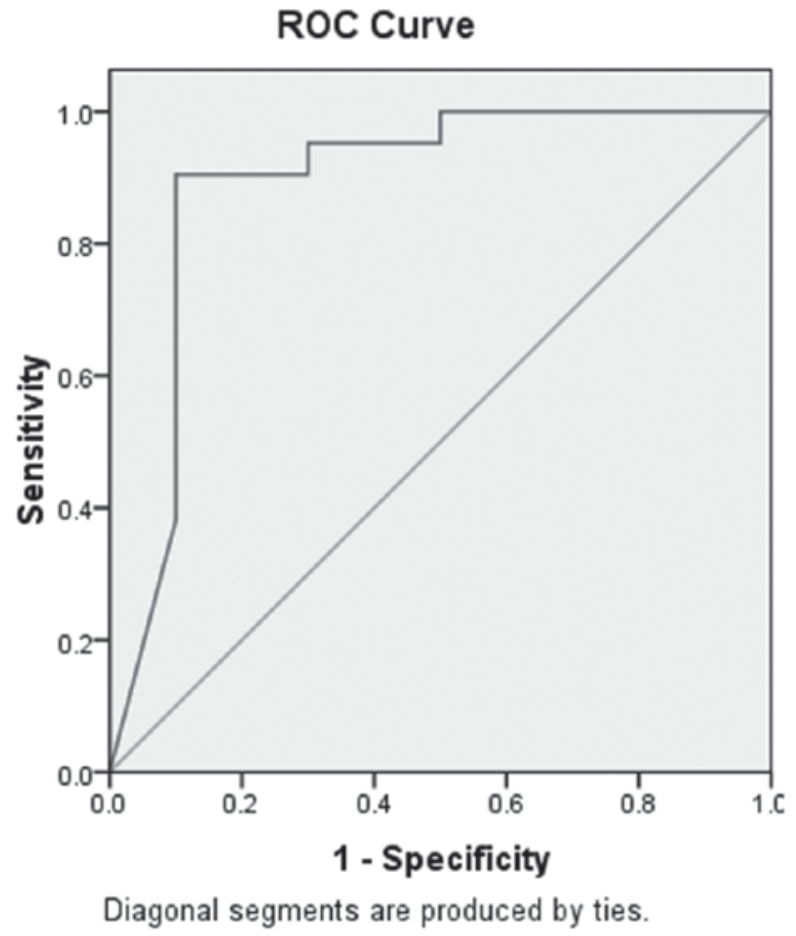

Figure 5: ROC curve of NT-proBNP in prediction of outcome (septic shock group)

[AUC $=0.890]$, cut-off value $13744.5 \mathrm{pg} / \mathrm{ml}$ with sensitivity $=90.5 \%$, specificity $=90 \%$. 
costs of care noticed that certain comorbid conditions such as diabetes mellitus, chronic liver diseases, HIV and cancer have been suggested to increase the risk of developing sepsis.

In this study diabetes mellitus was the most common (83.5\%) co-morbidity and the predominant diagnoses were Pneumonia (58.3\%), DM (83.5\%), HTN (64.6\%), AKI (29.1\%), UTI $(30.7 \%)$. But in this study, no patient had HIV.

Engel et al. ${ }^{17}$ conduct epidemiology of sepsis in Germany and revealed respiratory and renal dysfunction were the most frequent organ dysfunctions ( $52.0 \%$ and $42.2 \%$, respectively) and the most frequent sites of infection were the respiratory tract $(62.9 \%)$ and the abdomen $(25.3 \%)$.

Greg et al. ${ }^{18}$ found the organs that failed most frequently in patients with sepsis were the lungs (in $18 \%$ of patients) and the kidneys (in $15 \%$ of patients).

Nguyen et al. ${ }^{19}$ found the predominant admission diagnoses were pneumonia and urosepsis, with $52.3 \%$ patients presenting in septic shock. But in this study, septic shock patient was $24.4 \%$ which may be due to strict inclusion and exclusion criteria.

In our study among 127 patients, $24.4 \%(n=31)$ were in septic shock and $75.6 \%(n=96)$ patients present with severe sepsis. There was no difference in the presence of septic shock between men and women.

Among 31 (24.4\%) septic shock patients, 32.2\% ( $\mathrm{n}=10)$ patients were survivor and NT-proBNP level was $7333.50 \pm$ $10624 \mathrm{pg} / \mathrm{ml} ; 67.8 \%(\mathrm{n}=21)$ patients were non survivor and NT-proBNP level was $24908.38 \pm 10017.87 \mathrm{pg} / \mathrm{ml}(P$ $<0.001)$.

In this study among $96(75.6 \%)$ patients with severe sepsis, $88.7 \%(\mathrm{n}=86)$ were survivor andNT-proBNP level was $2436.41 \pm 3755.03 \mathrm{pg} / \mathrm{ml} ; 11.3 \%(\mathrm{n}=11)$ patients were non-survivors and NT-proBNP level was $21238.36 \pm$ $10095.34 \mathrm{pg} / \mathrm{ml}(P<0.0001)$.

Brueckmannet $\mathrm{al}^{11}$. found that in 57 severe sepsis patients, NT-proBNP level of survivors and non survivors were statistically significant $(P<0.01)$. Septic patients with NT-proBNP level $>11,800 \mathrm{pg} / \mathrm{ml}$ were 3.9 times more likely to die of sepsis than patients with lower NT-proBNP values. They also confirmed that, after doing correction for potential confounding factors with Cox regression, NT-proBNP was a highly significant parameter predicting mortality in their patient population. ROC curve of that study showed that area under the curve [AUC] was 0.68 , cut off limit of $11800 \mathrm{pg} / \mathrm{ml}$.

In this study we found that patients with severe sepsis NT-proBNP level of survivors was significantly higher than that of non survivors $(P<0.0001)$ and ROC curve showed that area under the curve [AUC] was 0.94, cutoff limit of $9291.5 \mathrm{pg} / \mathrm{ml}$.

Varpulaet al. ${ }^{20}$ showed that in patients with severe sepsis and septic shock mortality was $26 \%$. In this study we found that mortality of $25.2 \%$ in patients with severe sepsis and septic shock.
Sturgesset al. ${ }^{21}$ found that in patients with septic shock mortality was $29 \%$. In this study we found that mortality of $67.8 \%$ in patients with septic shock.

Rochet al. ${ }^{22}$ found that in patients with septic shock, NT-proBNP level $>13600 \mathrm{pg} / \mathrm{ml}$ predicts ICU mortality with an accuracy of $77 \%$ \& Area under the ROC curve [AUC] was 0.8. In this study, patients with septic shock, NT-proBNP cutoff level was $13744.5 \mathrm{pg} / \mathrm{ml} \&$ Area under the ROC curve [AUC] was 0.89 .

Median NT-proBNP level varies among Varpula et al. ${ }^{20}$, Roch et al. ${ }^{22}$ and this study might be due to a more diverse patient population.

Opposite to this study, in a small study by Rudigeretal ${ }^{12}$. found that neither BNP nor NT-proBNP was predictive for ICU or hospital mortality in 24 patients with septic shock.

The present study extends the concept of increased level of NT-proBNP may warn the ICU professional about sepsis induced cardiac dysfunctions and associated with increased rate of mortality.During resuscitation of sepsis, especially during aggressive fluid management, increased NT-proBNP level should keep in mind.Initial serial NT-proBNP measurements in the presence of SIRS alert the clinician to the severity of illness and may be associated with outcome.

\section{Limitations:}

As the sample size was small, the findings derived from study cannot be generalized to reference population and the data should be interpreted with utmost caution. This study was conducted in a tertiary care hospital where most of the patient population were diabetic, CKD and having preexisting multiple co-morbidities.

\section{Conclusion:}

Severe sepsis and septic shock are the leading cause of ICU admission and also leading cause of death. Physician and health care professional should promptly address the sepsis as a medical emergency and also should grow awareness about early diagnosis and optimal management of sepsis. This study described the epidemiologic profile of patients with severe sepsis and septic shock in an ICU in the city of Dhaka, Bangladesh in a tertiary care hospital with predominantly diabetic population. This study shows that, elderly patient with DM had developed sepsis more. Pneumonia and UTI are common cause of severe sepsis and septic shock. Sepsis causes extreme inflammatory reactions involving all organs of whole body including heart, causing release of NT-proBNP. Raised level of this biomarker associated with increased rate of mortality.

\section{References:}

1. Malmir J, Bolvardi E, Afzal Aghaee M. Serum lactate is a useful predictor of death in severe sepsis and septic shock. Reviews in Clinical Medicine 2014; 1(3): 97-104.

2. Martin GS, Mannino DM, Eaton S, Moss M. The Epidemiology of Sepsis in the United States from 1979 through 2000.New Engl J Med. 2003; 348:1546-54. 
3. Parrillo JE, Dellinger RP. Critical care medicine: principles of diagnosis and management in the adult. Philadelphia: Elsevier; 2104.

4. Levy MM, Fink MP, Marshall JC, Abraham E, Angus D, Cook D, et al .SCCM/ ESICIM/ ACCP/ATI/ SIS international Sepsis definitions Conference. Crit. Care Med. 2003; 31: 1250-6.

5. Wheeler AP, Bernard GR. Treating patients with severe sepsis. N Engl J Med. 1999; 340: 207-14.

6. Dellinger RP. From the bench to the bedside: The future of sepsis research. Executive summary of an American College of Chest Physicians, National Institute of Allergy and Infectious Disease, and National Heart, Lung, and Blood Institute Workshop. Chest. 1997;111:744-53.

7. GulloA, Bianco N, BerlotG. Management of severe sepsis and septic shock: challenges and recommendations.Crit Care Clin. 2006; 22:489-501.

8. Hotchkiss RS, Karl IE. The pathophysiology and treatment of sepsis. N Engl J Med. 2003;348:138-50.

9. Angus DC, Walter T, Linde- Zwirble, Lidicker J, Clermont G, Carcillo J, et al. Epidemiology of severe sepsis in the United States: Analysis of incidence, outcome, and associated costs of care. Crit Care Med. 2001; 29(7):1303 -10.

10. Januzzi JL, Morss A, Tung R, Pino R, Fifer MA, Thompson BT, et al. Natriuretic peptide testing for the evaluation of critically ill patients with shock in the intensive care unit: a prospective cohort study.Crit Care. 2006; 10: R37.

11. Brueckmann M, Huhle G, Lang S, Haase KK, Bertsch T, Weiss C, et al. Prognostic value of plasma $\mathrm{N}$-terminal pro-brain natriuretic peptide in patients with severe sepsis.Circulation. 2005; $112: 527-34$.

12. RudigerA, Singer M. Mechanisms of sepsis-induced cardiac dysfunction.Crit Care Med. 2007; 35:1599-608.

13. Knaus WA, Draper EA, Wagner DP, Zimmermann JE. APACHE II: a severity of disease classification system.Crit Care Med. 1985; 13: $818-29$.
14. Le GallJR, Lemeshow S, Saulnier F.A new Simplified Acute Physiology Score (SAPS II) based on a European/North American multicenter study.JAMA. 1993; 270:2957-63 [published erratum appears in JAMA 1994; 271:1321].

15. Kandil E, Burack J, Sawas A, Bibawy H, Schwartzman A, Zenilman $\mathrm{ME}$, et al. B-type natriuretic peptide: a biomarker for the diagnosis and risk stratification of patients with septic shock.Arch Surg. 2008; $143: 242-6$.

16. Guidet B, Aegerter P, Gauzit R, Meshaka P, Dreyfuss D.Incidence and impact of organ dysfunctions associated with sepsis.Chest. 2005; 127(3):942-51.

17. Engel C, Frank M, Bone HG, Brunkhorst R, Gerlach H.Epidemiology of sepsis in Germany: results from a national prospective multicenter study. Intensive Care Med. 2007; 33: 606-18.

18. Greg S, Martin M, David M, Eaton S, Marc M. The Epidemiology of Sepsis in the United States from 1979 through 2000.New Engl J Med. 2003; 348:1546-54.

19. Nguyen HB, Rivers EP, Knoblich BP, Jacobseen G, Muzzin A, Julie A, et al. Early lactate clearance is associated with improved outcome in severe sepsis and septic shock. Crit Care Med. 2004; 32(8):1637-42.

20. Varpula M, Pulkki K, Karlsson S, RuokonenE, Pettilä V.FINNSEPSIS Study Group. Predictive value of N-terminal pro-brain natriuretic peptide in severe sepsis and septic shock. Crit Care Med.2007;35:1277-83.

21. Sturgess DJ, Marwick TH, Joyce C, Jenkins C, Jones M, Masci P, et al. Prediction of hospital outcome in septic shock: a prospective comparison of tissue Doppler and cardiac biomarkers.Crit Care. 2010;14:R44.

22. Roch A, Allardet-Servent J, Michelet P, Oddoze C, Forel JM, Barrau K, et al. NH2 terminal pro-brain natriuretic peptide plasma level as an early marker of prognosis and cardiac dysfunction in septic shock patients. Crit Care Med. 2005; 33:1001-7. 